\title{
Convergencia de COBIT e ISO 3850s0 en el Gobierno de Tecnologías de la Información
}

\section{Convergence of COBIT and ISO 38500 in the government of technologies of information}

\author{
Darío Javier Robayo Jácome \\ https://orcid.org/0000-0002-0661-6573 \\ Pontificia Universidad Católica del Ecuador, Ecuador \\ Verónica De Las Mercedes Villarreal Morales \\ https://orcid.org/0000-0002-6401-3404 \\ Universidad Estatal Amazónica, Ecuador
}

Autor por correspondencia: drobayo@pucesa.edu.ec; vvillarreal@uea.edu.ec

Fecha de recepción: 20 de agosto de 2019 - Fecha de aceptación: 24 de enero de 2020

\section{Resumen}

El objetivo del proyecto de investigación fue la implementación de un Modelo de Gestión y Gobierno de Tecnologías de la Información en la Universidad Estatal Amazónica (UEA). El desarrollo se inició con una revisión del estado del arte seguido de la aplicación del ciclo de vida y la técnica de cascada de metas que contempla ISACA a través de su marco de referencia COBIT 5; todo esto aplicado junto con los principios que se establecen en la norma internacional ISO 38500 (2015), garantizó que la UEA aplique buenas prácticas de Gobierno de Tecnologías de la Información (TI) dotando de valor adicional a los procesos y estableciendo directrices para la mitigación de riesgos. Este modelo permitió a la UEA conjugar los objetivos de TI con los objetivos estratégicos institucionales, agregando valor y satisfaciendo las necesidades de cada dependencia a través de la administración de recursos (aplicaciones e infraestructura de TI) y la medición del desempeño de procesos relacionados con las TI. Al final, se evidenció que la adopción de este Gobierno fue altamente satisfactoria ya que los resultados obtenidos en el corto plazo reflejan la optimización y mejor aprovechamiento de los recursos de TI.

Palabras clave: gestión de TI; gobierno de TI; COBIT; ISO 38500

\begin{abstract}
The objective of this research project was the implementation of a Management and Governance Model of Information Technologies in the Estatal Amazonica University (EAU). The development began with a review of the state of the art followed by the application of the life cycle and the technique of cascading goals that ISACA contemplates through its COBIT 5 framework; all this applied together with the principles established in the international standard ISO 38500 (2015), guaranteed that the EAU applies good practices of Government of Information Technology (IT) giving additional value to the processes and establishing guidelines for mitigation of risks. This model allowed the EAU to combine IT objectives with institutional strategic objectives, adding value and meeting the needs of each unit through the
\end{abstract}


administration of resources (IT applications and infrastructure) and the measurement of the performance of IT-related processes. In the end it was evident that the adoption of this Government was highly satisfactory since the results obtained in the short term reflect the optimization and better use of IT resources.

Key words: TI management; TI governance; COBIT; ISO 38500

\section{Introducción}

La Universidad Estatal Amazónica (UEA) ha basado la administración de sus recursos de TI solamente en el conocimiento del personal de la Unidad de Tecnologías de la Información y Comunicaciones (UTIC), sin considerar modelos de procesos, políticas o estrategias que fomenten el alcance de los objetivos institucionales. Esta unidad se guía en lineamientos detallados en el plan estratégico de desarrollo institucional, el cual entre otras tiene como misión "promover la innovación y el desarrollo tecnológico, mediante la explotación de los resultados de la investigación y la transferencia de tecnología, administrar y controlar los recursos tecnológicos especializados que son propiedad de la institución, asesorar en la adquisición de equipos especializados, hardware y software" para la UEA (Universidad Estatal Amazónica, 2012).

La UTIC presenta limitaciones en la realización de sus procesos ya que no es independiente y se encuentra dentro de otro departamento, las metas definidas se enfocan en cubrir algunas necesidades tecnológicas actuales a corto plazo, ya que carecen de estrategias para lograrse en el largo plazo. Si bien, esta unidad viene cumpliendo con el proceso de gestión de tecnologías, dista en demasía de un verdadero gobierno de TI; está formada por un equipo humano pequeño -organizado desde el punto de vista de sus responsabilidades en las áreas de redes y telecomunicaciones, administración de servicios educativos y desarrollo de software-, que gestiona las demandas de toda la institución. El crecimiento representativo de la UEA hace notoria la carencia en estrategias tecnológicas, por lo que, la implementación de un modelo de gestión y gobierno de TI que integre y apoye la institucionalización de buenas prácticas de planificación, organización y monitoreo, provee una estructura necesaria que una los procesos y recursos de TI con los objetivos estratégicos institucionales a través del aseguramiento de la información administrada y las tecnologías empleadas.

Con base a la problemática expuesta y de acuerdo con Marulanda, López \& Valencia (2017), la implementación de un modelo de gestión y gobierno de TI significa un cambio en políticas, procesos, responsabilidad organizativa y estándares; orientados a la obtención de una adecuada gobernabilidad que mitigue los riesgos y satisfaga las necesidades de los distintos ejes de desarrollo. Lo expuesto, hace que este proyecto sea el inicio del cambio en la forma de administración, apoyándose en el cumplimiento del ciclo de vida propuesto por la Information Systems Audit and Control Association (ISACA) en su marco de referencia COBIT 5 (ISACA, 2012) y alineado a los principios de la ISO 38500 (Hamidovic, 2011), permitiendo alcanzar nuevas directrices en el manejo de procesos apoyados por la tecnología.

\section{Estado del Arte}

Dentro de la CRUE (Conferencia de Rectores de Universidades Españolas), los autores Fernández \& Llorens (2011), presentan el proyecto: Gobierno de TI para universidades, en el cual utilizan COBIT 5 e ISO 38500 como base para el diseño y creación 
de un marco de referencia de gobierno de TI para Universidades, mismo que, entre sus resultados menciona la conjunción del gobierno de TI con las necesidades de las Universidades españolas complementado con la autoevaluación de la madurez de los procesos implicados. Los autores concluyen que la contribución de la integración de COBIT 5 e ISO 38500 permiten entre otras cosas evaluar opciones estratégicas para la dirección de TI, lo cual, junto a la supervisión de resultados, propician un acercamiento de la implementación de estándares ISO dentro de las instituciones de educación superior.

En ese mismo contexto, sierra (2012) describe un estudio de la implantación de gobierno de TI en las universidades en su proyecto titulado: “¿Cómo implantar el Gobierno de las Tecnologías de la Información en Instituciones de Educación Superior?”, en el cual se describen los elementos y herramientas que las universidades han utilizado para la implantación de gobierno de TI. Para este estudio, fueron evaluadas 79 universidades a nivel mundial, lo que llevo a un análisis de los resultados obtenidos y se los enmarcó en un conjunto de buenas prácticas para la implementación del gobierno en otras universidades.

Si bien, el aporte de estos trabajos es significativo, pueden distar aún de ser unas verdaderas guías de implementación, por lo que la tesis doctoral de Fernández (2009), es un aporte complementario, puesto que, propone mejorar el gobierno, la administración y la planificación de las TI en las universidades españolas mediante la utilización de herramientas de gobierno corporativo. El trabajo se lo realizó en dos fases: la primera cuyo objetivo fue analizar la situación de las TI en el Sistema Universitario Español (SUE) para proponer acciones de mejora tanto a nivel global (para todo el SUE) como a nivel local (para cada una de las universidades); la segunda, cuya finalidad fue descubrir cuál puede ser la importancia del gobierno de las TI para las universidades españolas, haciendo que el resultado se convierta en un referente global y así proponer el cumplimiento de las acciones de implantación de dicho modelo. El autor concluye que la explotación de los modelos diseñados durante el proceso de investigación proporcionará suficiente información que contribuirá a la realización de estudios sobre la alineación de las TI y los objetivos institucionales y el análisis del valor que las TI proporcionan a las universidades.

Haciendo un acercamiento a la zona latinoamericana, Salazar \& Vela (2012) desarrollan el proyecto Gobierno de TI en Colombia: documentación y modelado de procesos que soportan el Gobierno y la Gestión de las Tecnologías de Información, dentro de la Universidad ICESI de Santiago de Cali, el cual, propone como paso inicial la documentación y el modelado de procesos, para facilitar así la implementación del gobierno de TI bajo el marco de referencia COBIT; de esta manera, se complementa lo expuesto anteriormente ya que este sería un importante primer paso para la implantación del gobierno. De este trabajo como premisa principal se ha de mencionar, que el éxito para tal implantación inicia con la toma de conciencia de la dirección o altos ejecutivos de la organización sobre el valor que aporta el gobierno de TI.

En el contexto nacional, Valverde, Mejía \& Meza (2017), proponen mejorar continuamente los procesos, la gestión estratégica y la aplicación de tecnologías de información y comunicación en los procesos académicos dentro del entorno universitario público del Ecuador, lo que posibilitará herramientas a los estudiantes para optimizar los servicios prestados por el estado, agilizar y simplificar los procesos y procedimientos administrativos, con una gobernanza de las TI apropiada y el aprovechamiento continuo del 
desarrollo de tecnologías de información y comunicación. Es importante contar con una alta dirección eficiente, con mecanismos de evaluación que permitan mejorar su desempeño y la calidad de los servicios; que simplifique los procesos académicos con herramientas más óptimas y eficientes y rinda cuentas de manera clara y oportuna a los beneficiarios que en el caso universitario son los estudiantes. Además, con la utilización de COBIT 5 y la adaptación de los procesos de gobierno de TI para evaluar el cumplimiento de procesos de gobernanza en la Universidad Central del Ecuador, se generó una línea base de resultados a través del uso del modelo de niveles de madurez propuesto por el GTI4U, lo cual, junto con observar el comportamiento de una universidad pública del Ecuador respecto al cumplimiento de gobernanza corporativa de las TI, hace que los resultados obtenidos generen una línea base que apoye a futuro a la generación de un marco de gobierno específico para universidades públicas del Ecuador.

Sobre la misma línea Morales (2015), concluye que el principal problema para la implementación del gobierno de TI de forma específica en las Instituciones de Educación Superior es que no existe una metodología clara y definida para el efecto. Esto quizás porque como paso previo a la implementación del Gobierno TI en las Universidades se deben establecer políticas que generen confianza entre beneficiarios y autoridades, lo que podría dificultar el establecimiento de una metodología. Además, menciona que no existe un modelo específico para la implementación del Gobierno TI en Universidades Sudamericanas; por lo que, cuando los investigadores diseñen y validen un modelo de Gobierno TI particularizado, deben desarrollar todas las herramientas que proporcionen una clara idea de la forma de implementación, así como todo el soporte adecuado.

\section{Metodología}

\section{Gobierno de TI}

Para Hamidovic (2011), gobierno corporativo es un "proceso mediante el cual la junta de directores a través de la gerencia, guía a la institución en el cumplimiento de su misión corporativa y protección de sus activos", por lo que tiene trascendencia dentro de las empresas privadas y con un alza en la implementación dentro de las empresas públicas (Coba, Díaz \& Altamirano, 2018). En consecuencia, al ser el modelo corporativo de las universidades similar al implementado por las empresas, se componen habitualmente de una estructura jerárquica similar la cual se aplica en la mayoría de las instituciones (Flórez \& Lopez, 2014); ya que estas también buscan ser dirigidas por profesionales con experiencia en diversas áreas de gestión y dirección.

El concepto de gobierno es utilizado también en el área de tecnologías como Gobierno de TI, cuyo propósito es "el alineamiento de los objetivos institucionales con los recursos y estrategias de TI" (Changmarín, 2018). Según ISACA (2012), el Gobierno de TI es considerado como "el encargado de asegurar que se consideren las necesidades, condiciones y opciones de las partes interesadas para determinar que se alcancen las metas corporativas equilibradas y acordadas; estableciendo la dirección a través de la priorización y la toma de decisiones y midiendo el rendimiento y el cumplimiento respecto a la dirección en función de las metas acordadas", lo que conlleva la aplicación de buenas prácticas que permitan la unión de la arquitectura de información, los procesos y recursos de TI, con las estrategias y los objetivos de la Institución de Educación Superior (IES) (Villarreal, 2018). 
Para que exista efectividad del gobierno de TI, los elementos que lo constituyen deben están relacionados con las personas, es decir, debe existir entre otras cosas el apoyo de los directivos, el aprovechamiento de las destrezas y las capacidades personales y la alta participación e implicación de todos los grupos de interés (Solares, 2014); por ello es recomendable que los directores de TI realicen una evaluación constante de las tendencias tecnológicas en las universidades, de manera que puedan asumir un rol crítico y complementario en la realización de propuestas que se planteen por parte de los usuarios institucionales (Chinkes, 2015).

\section{Marcos de referencia}

Al momento existen una gran cantidad de modelos, marcos de referencia y estándares que permiten la implementación de un gobierno de TI. Entre los más destacados y que han fundamentado nuevos modelos están: COBIT en su última versión 5 que une COBIT4.1, Val IT 2.0, Risk IT, BMIS (ISACA, 2012); e ISO 38500, norma diseñada exclusivamente para el Gobierno de TI (Fachry, Maullana \& Fathonah, 2018).

\section{COBIT}

Este marco de trabajo que es el principal modelo seguido a escala mundial (Yrigoyen, 2016), provee un modelo integral que ayuda a las empresas a alcanzar sus objetivos para el gobierno y la gestión de TI, ayudando a las empresas a crear un valor óptimo manteniendo el equilibrio entre la generación de beneficios y la optimización de los niveles de riesgo y el uso de recursos (ISACA 2012). La versión 5 de COBIT que según ISACA (2012) une COBIT4.1, Val IT 2.0, Risk IT y BMIS; está basada en cinco principios que se aplican con la técnica de cascada de metas, estos son: satisfacer las necesidades de las partes interesadas, cubrir la empresa extremo-a-extremo, aplicar un marco de referencia único integrado, hacer posible un enfoque holístico, separar el gobierno de la gestión (Camino 2017). Medina, Areniz \& Rico (2016), mencionan que el gobierno de TI no solo debe quedarse en la implementación, sino que se debe evaluar su madurez a través del tiempo de aplicación, lo que en palabras de Chinkes (2015) es fundamental para mostrar con objetividad los resultados y para establecer acuerdos de niveles de servicio y/o de nivel operacional, tanto con los usuarios como con las autoridades de la universidad.

ISO 38500

La norma ISO/IEC 38500:2008 "Corporate Governance of Information Technology" nace en el año 2005 como el estándar AS8015-2005 mismo que, en el 2008 fue promovido a norma internacional (Valencia, Marulanda \& López, 2018). Esta norma de acuerdo con Ballester (2010) trata sobre procesos y decisiones de los servicios de información, considerando que éstos pueden estar administrados tanto por personal interno o externo. Esta norma puede guiar a la obtención del máximo valor de los recursos de información, sentando las bases de un marco de referencia para un gobierno eficiente de TI. (Citado en Villarreal, 2018) Es así como, la norma ISO 385000 permite incentivar el uso eficiente y de las TI alineado a los objetivos corporativos. Para ello y entre otros aspectos, "la norma se basa en seis principios que expresan cuales son los comportamientos que deben adoptarse y que es lo que se debe hacer, pero no indican cómo ni quién debe hacerlo. Estos principios son 
responsabilidad, estrategia, adquisición, rendimiento, conformidad y factor humano" (Villarreal, 2018).

\section{Desarrollo}

Para el inicio de la implementación, lo primero es crear un entorno apropiado para asegurar el éxito de la implementación o de la iniciativa de mejora, por lo que las siete fases de COBIT (ISACA, 2012) y la aceptación de los principios de la ISO 38500, son utilizados para este propósito (Enriquez, Valverde \& Llorens, 2017) (Citado por Villarreal, 2018). Parte de este inicio es el análisis y la concientización por parte de los directivos, de los aspectos que se deben mejorar para fortalecer las metas trazadas mediante el apoyo y el uso adecuado de las TI.

\section{Fase 1. Aceptación de la necesidad de cambio}

Una vez determinada la problemática de la UTIC, la dirección, entendiendo la necesidad de cambio en la forma de administrar las TI en la UEA, sociabiliza las ventajas y viabilidad de un gobierno para la gestión de TI a la máxima autoridad de la institución, luego de lo cual se cuenta con la aprobación para iniciar el proceso de implementación del modelo. (Villarreal, 2018) Para ello se recomienda iniciar con acciones formativas desde la alta dirección, para promulgar las ventajas de un estándar de gobernanza de las TI en la institución, logrando con esto definir en conjunto las acciones necesarias para que la iniciativa trascienda en cada dependencia, facilitando así la implementación. (Velásquez, Puentes \& Pérez, 2015).

\section{Fase 2. Evaluación estado actual}

En esta etapa se pudo determinar principalmente que no existe el involucramiento de las autoridades como agentes partícipes de las decisiones y administración de tecnologías; además, estas son gestionadas con base en el conocimiento del personal involucrado, sin seguir lineamientos de normas o estándares y sin la utilización de proyectos que permitan monitorear y supervisar avances y resultados. (Villarreal, 2018).

Complementando lo expuesto, se pudo identificar además que la UEA no cuenta con una estructura organizacional de TI que defina roles y responsabilidades de cada persona involucrada con las decisiones y gestión, y que cubra la demanda de toda la comunidad universitaria, no se cuenta con políticas que definan la propiedad y los parámetros de seguridad de la información, no se han definido procesos para el desarrollo de software, no existe una adecuada planificación para gestión de riesgos, carencia de procesos de evaluación y mejora continua, entre otros. Sin embargo, y de acuerdo con Villarreal (2018) la problemática más evidente es el no alineamiento estratégico entre los objetivos institucionales y los de TI, por lo que a partir de los objetivos institucionales de la UEA, se aplica la técnica de cascada que establece las metas corporativas de COBIT 5 (ISACA 2012), realizando el mapeo con la escala $\mathrm{P}$ de Relación principal, usada cuando las metas genéricas de COBIT 5 corresponden a las metas institucionales y en la que COBIT permite traducir las prioridades estratégicas a 'ponderaciones' para un mejor uso de la técnica, dándole a esta escala un valor de 5. Además, se usó la escala $\mathrm{S}$ de Relación secundaria, útil cuando las metas genéricas de COBIT 5 no corresponden, pero están enlazadas a las metas institucionales; se le 
asignó el valor de 2. La Tabla 1 muestra el mapeo entre las metas de la UEA y las metas corporativas de COBIT 5.

Tabla 1

Proceso de mapeo metas UEA y metas corporativas COBIT

\begin{tabular}{|c|c|c|c|c|c|c|c|c|c|c|c|c|c|c|c|c|c|c|}
\hline & \multicolumn{17}{|c|}{ META CORPORATIVA } \\
\hline & & 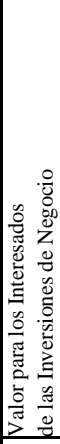 & 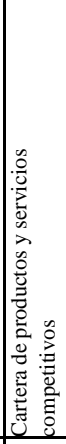 & 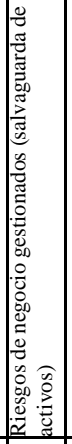 & 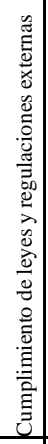 & 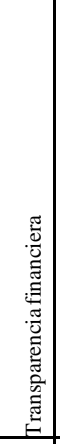 & 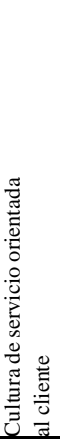 & 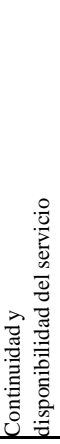 & 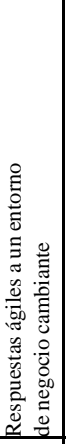 & 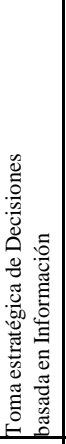 & 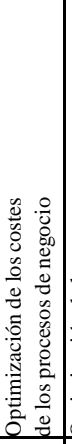 & 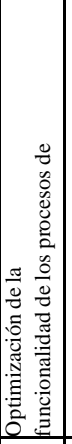 & 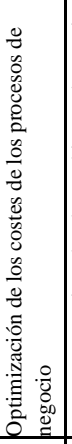 & 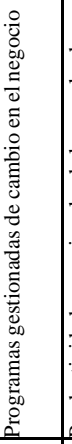 & 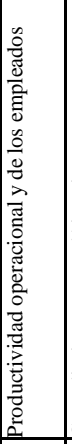 & 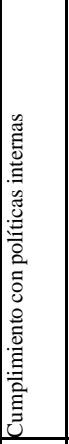 & 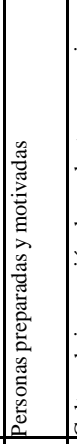 & 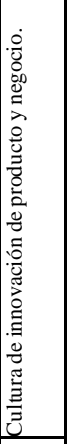 \\
\hline & & & 2 & 3 & 4 & 5 & 6 & 7 & 8 & 9 & 10 & 11 & 12 & 13 & 14 & 15 & 16 & 17 \\
\hline \multicolumn{2}{|c|}{$\begin{array}{l}\text { META UNIVERSIDAD ESTATAL } \\
\text { AMAZONICA } \\
\end{array}$} & \multicolumn{5}{|c|}{ FINANCIERA } & \multicolumn{5}{|c|}{ CLIENTE } & \multicolumn{5}{|c|}{ INTERNA } & \multicolumn{2}{|c|}{$\begin{array}{c}\text { APRENDIZA } \\
\text { JE Y } \\
\text { CRECIMIEN } \\
\end{array}$} \\
\hline $\begin{array}{l}\text { Obj. } \\
01\end{array}$ & $\begin{array}{l}\text { Potenciar la investigación científica } \\
\text { básica y aplicada con mayor } \\
\text { enfoque en la biodiversidad y los } \\
\text { recursos de la región, } \\
\text { sistematizando y difundiendo, los } \\
\text { conocimientos ancestrales, las } \\
\text { tecnologías, arte y cultura de los } \\
\text { diferentes pueblos y nacionalidades } \\
\text { amazónicas, bajo estándares de } \\
\text { rigurosidad, disciplina académica y } \\
\text { responsabilidad, enfocada a la } \\
\text { generación de nuevo conocimiento, } \\
\text { y desarrollo tecnológico con } \\
\text { compromiso social para la } \\
\text { generación de patentes }\end{array}$ & $\mathbf{P}$ & $\mathbf{S}$ & & $\mathbf{P}$ & S & $\mathbf{s}$ & $\mathbf{P}$ & & S & & & & & $s$ & S & $\mathbf{P}$ & $\mathbf{P}$ \\
\hline $\begin{array}{l}\text { Obj. } \\
02\end{array}$ & $\begin{array}{l}\text { Ejecutar procesos educativos de } \\
\text { pregrado y posgrado, que permitan } \\
\text { formar profesionales competentes e } \\
\text { innovadores, capaces de generar } \\
\text { nuevos conocimientos a través de } \\
\text { la investigación científica y } \\
\text { resolver los problemas locales, } \\
\text { regionales y nacionales. }\end{array}$ & $\mathbf{P}$ & $\mathbf{P}$ & & $\mathbf{P}$ & & $\mathbf{P}$ & $\mathbf{P}$ & S & S & & & & & S & S & $\mathbf{P}$ & S \\
\hline $\begin{array}{l}\text { Obj. } \\
03\end{array}$ & $\begin{array}{l}\text { Contribuir al desarrollo local, } \\
\text { regional y nacional, propiciando } \\
\text { una mejor interacción Universidad- } \\
\text { Sociedad mediante planes y } \\
\text { programas que contengan nuevas } \\
\text { alternativas, o modelos de vida y de } \\
\text { producción para solucionar los } \\
\text { problemas ambientales, sociales y } \\
\text { tecnológicos que permitan el } \\
\text { desarrollo equilibrado del hombre y } \\
\text { la conservación de la naturaleza de } \\
\text { la región amazónica. }\end{array}$ & $\mathbf{P}$ & & & $\mathbf{P}$ & & $\mathbf{P}$ & $\mathbf{P}$ & & $\mathbf{S}$ & & & & & S & $\mathbf{P}$ & S & \\
\hline $\begin{array}{l}\text { Obj. } \\
04\end{array}$ & $\begin{array}{l}\text { Mejorar la eficiencia en la gestión } \\
\text { administrativa para generar un } \\
\text { soporte organizado y operativo } \\
\text { eficiente enfocado hacia el logro } \\
\text { de la excelencia. }\end{array}$ & $\mathbf{P}$ & & & $\mathbf{P}$ & $\mathbf{P}$ & $\mathbf{P}$ & $\mathbf{P}$ & $\mathbf{P}$ & $\mathbf{P}$ & S & S & S & S & $\mathbf{P}$ & $\mathbf{P}$ & S & \\
\hline & & 20 & 7 & & 20 & 7 & 17 & 20 & 7 & 11 & 2 & 2 & 2 & 2 & 11 & 14 & 14 & 7 \\
\hline
\end{tabular}

Fuente: Villarreal (2018)

Esta obra se comparte bajo la licencia Creative Common Atribución-No Comercial 4.0 International (CC BY-NC 4.0) Revista de la Universidad Internacional del Ecuador. URL: https://www.uide.edu.ec/ 
Como resultado de lo anterior, la Tabla 2 muestra las metas corporativas genéricas de COBIT 5 que proporcionan el soporte para el cumplimiento de las metas de la UEA.

\section{Tabla 2}

Resultado mapeo metas UEA y metas corporativas COBIT

\begin{tabular}{cl}
\hline $\mathbf{N}^{\mathbf{0}}$ meta & Meta institucional UEA \\
\hline 1 & Valor para los Interesados de las Inversiones de Negocio \\
2 & Cumplimiento de leyes y regulaciones externas \\
3 & Cultura de servicio orientada al cliente \\
4 & Continuidad y disponibilidad del servicio de negocio \\
\hline
\end{tabular}

Fuente: Villarreal (2018)

Continuando con la aplicación de la metodología, se establece la relación entre las metas de la UEA y las metas relacionadas con TI que menciona COBIT; para ello se toma en cuenta la misma escala de ponderación utilizada anteriormente. El resultado de ese proceso se muestra en la Tabla 3, en la que se resaltan las metas de TI que son necesarias para alcanzar las metas de la IES:

- Alineamiento de TI y la estrategia de negocio

- Entrega de servicios de TI de acuerdo a los requisitos del negocio

- Seguridad de la información, infraestructura de procesamiento y aplicaciones 
Tabla 3

Cascada de metas, mapeo metas corporativas COBIT y metas relacionadas con TI

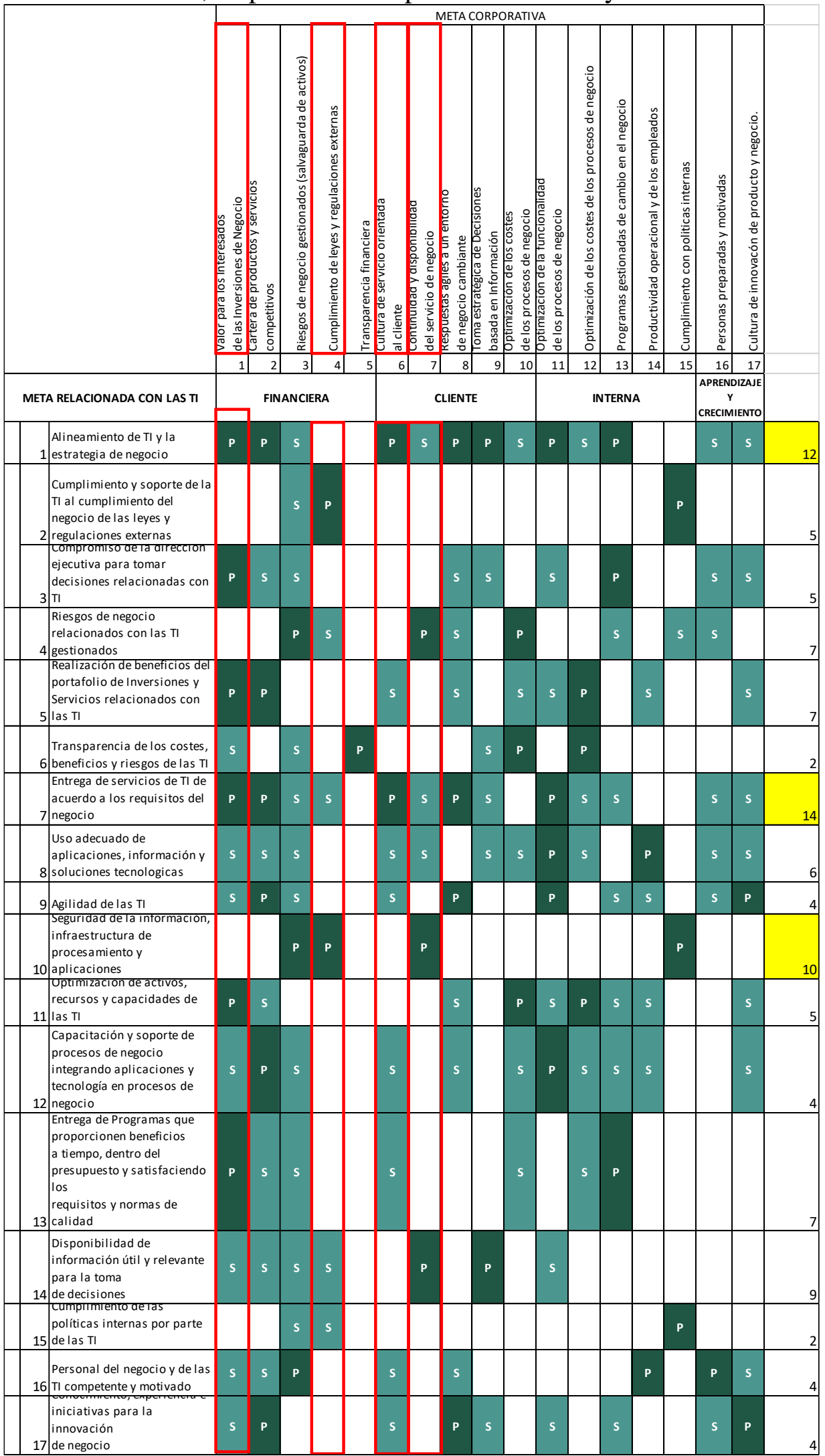

Fuente: Villarreal (2018) 


\section{Tabla 4}

Mapeo metas relacionadas con TI y procesos COBIT

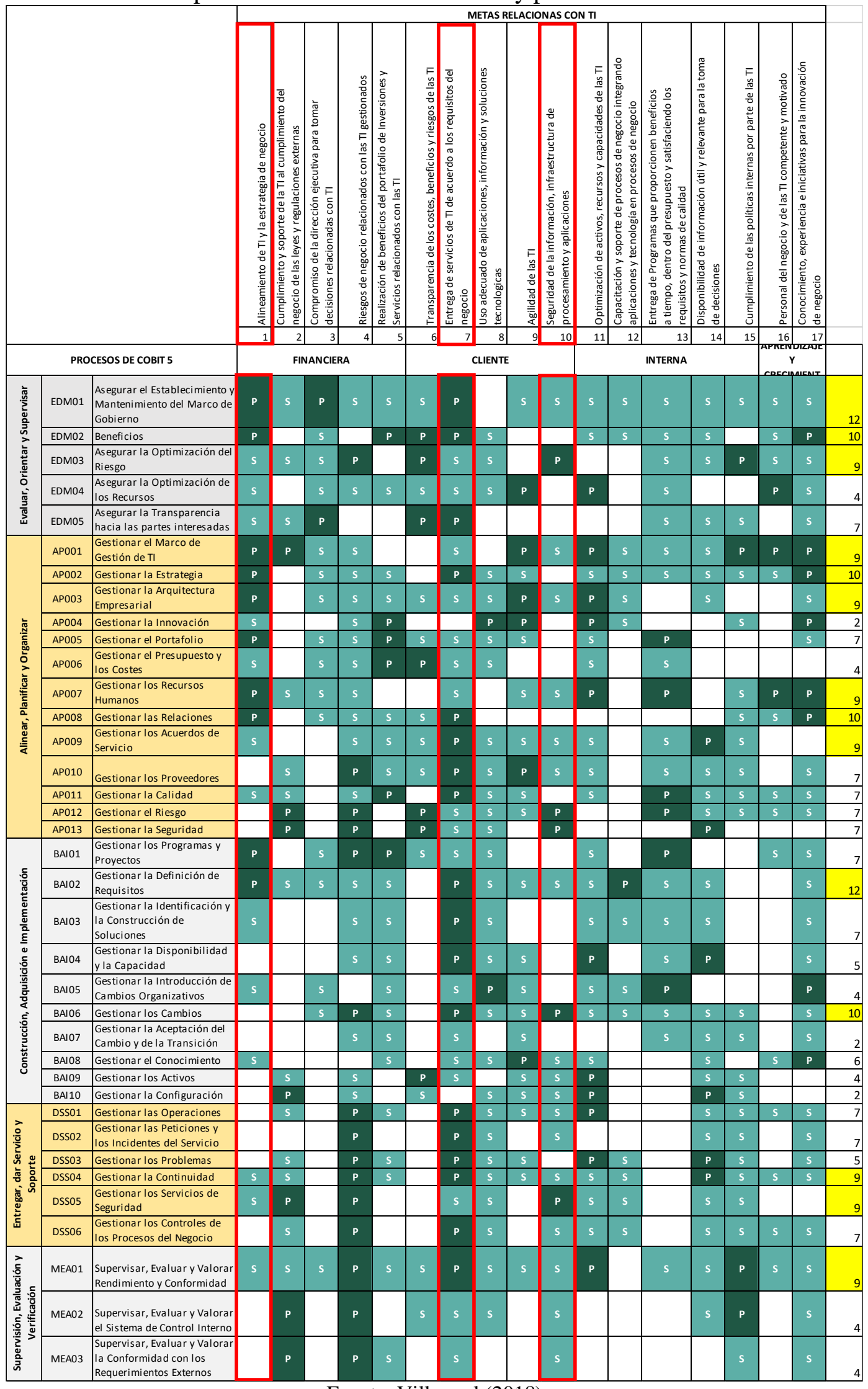

Fuente: Villarreal (2018) 
Con las metas identificadas se continúa con la técnica para determinar los procesos de COBIT que serán utilizados como catalizadores para apoyar la implementación del gobierno, los cuales vienen a ser de manera general aspectos que pueden ayudar a conseguir las metas de la empresa (ver Tabla 4). Como resultado se obtienen los procesos de gobierno para alcanzar los objetivos institucionales (ver Tabla 5), y los procesos de gestión de TI aplicables (ver Tabla 6).

Tabla 5

Procesos de Gobierno de TI

\begin{tabular}{ll}
\hline Evaluar, Orientar Y Supervisar \\
\hline EDM01 & Asegurar el establecimiento y mantenimiento de Marco de Gobierno \\
EDM02 & Asegurar la entrega de beneficios \\
EDM03 & Asegurar la Optimización del Riesgo \\
\hline
\end{tabular}

Fuente: Adaptado de Villarreal (2018)

\section{Tabla 6}

Procesos de Gestión de TI

\begin{tabular}{ll}
\hline Alinear, Planificar Y Organizar \\
\hline AP001 & Gestionar el Marco de Gestión de TI \\
AP002 & Gestionar la estrategia \\
AP003 & Gestionar la arquitectura empresarial \\
AP007 & Gestionar los recursos humanos \\
AP008 & Gestionar las relaciones \\
AP009 & Gestionar los acuerdos de servicios \\
\hline Construcción, Adquisición E Implementación \\
\hline BAI02 & Gestionar la definición de requisitos \\
BAI06 & Gestionar los Cambios \\
\hline Entregar, Dar Servicio Y Soporte \\
\hline DSS04 & Gestionar la Continuidad \\
DSS05 & Gestionar los Servicios de Seguridad \\
\hline Supervisión, Evaluación Y Verificación \\
\hline MEA01 & Supervisar, Evaluar y Valorar Rendimiento y Conformidad \\
\hline \multicolumn{1}{l}{ Fuente: Adaptado de Villarreal (2018) }
\end{tabular}

Seguidamente se identificaron las entradas y salidas de información que guíen la implementación del modelo, lo que permitirá aplicar cambios considerables en las áreas de la UTIC asegurando así la aplicación de buenas prácticas. Esto permite definir procesos que, junto con los objetivos de la UEA, conducen a la valoración actual de la forma cómo se lleva el gobierno de TI, usando parámetros considerados en COBIT 5 e inspirados en la norma ISO 1554; los resultados permiten determinar y mejorar la capacidad en la organización, con el uso de los niveles de madurez (ver Tabla 7) establecidos en ISACA (2012), y las metas y procesos determinados. (Villarreal, 2018) Los resultados de esta etapa se resumen en la Figura 1. 
Tabla 7

Nivel de capacidad

\begin{tabular}{|c|c|}
\hline Nivel De Capacidad & Descripción \\
\hline 0 proceso incompleto & El proceso no existe o no alcanza su propósito. \\
\hline 1 proceso ejecutado & El proceso implementado alcanza su propósito. \\
\hline 2 proceso gestionado & $\begin{array}{l}\text { El proceso está implementado de forma gestionada } \\
\text { (planificado, supervisado y ajustado) y los resultados } \\
\text { de su ejecución están establecidos, controlados y } \\
\text { mantenidos apropiadamente. }\end{array}$ \\
\hline 3 proceso establecido & $\begin{array}{l}\text { El proceso está implementado usando un marco } \\
\text { definido para alcanzar sus resultados. }\end{array}$ \\
\hline 4 proceso predecible & $\begin{array}{l}\text { El proceso se ejecuta dentro de límites definidos para } \\
\text { alcanzar sus resultados. }\end{array}$ \\
\hline 5 proceso optimizado & $\begin{array}{l}\text { El proceso se convierte en buena práctica, sobre la base } \\
\text { de los resultados de mejora continua. Se automatizan } \\
\text { los flujos de trabajo, existen mecanismos para mejorar } \\
\text { la calidad y la efectividad, haciendo a la IES rápida } \\
\text { para adaptarse. }\end{array}$ \\
\hline
\end{tabular}

Fuente: Adaptado de Villareal (2018)

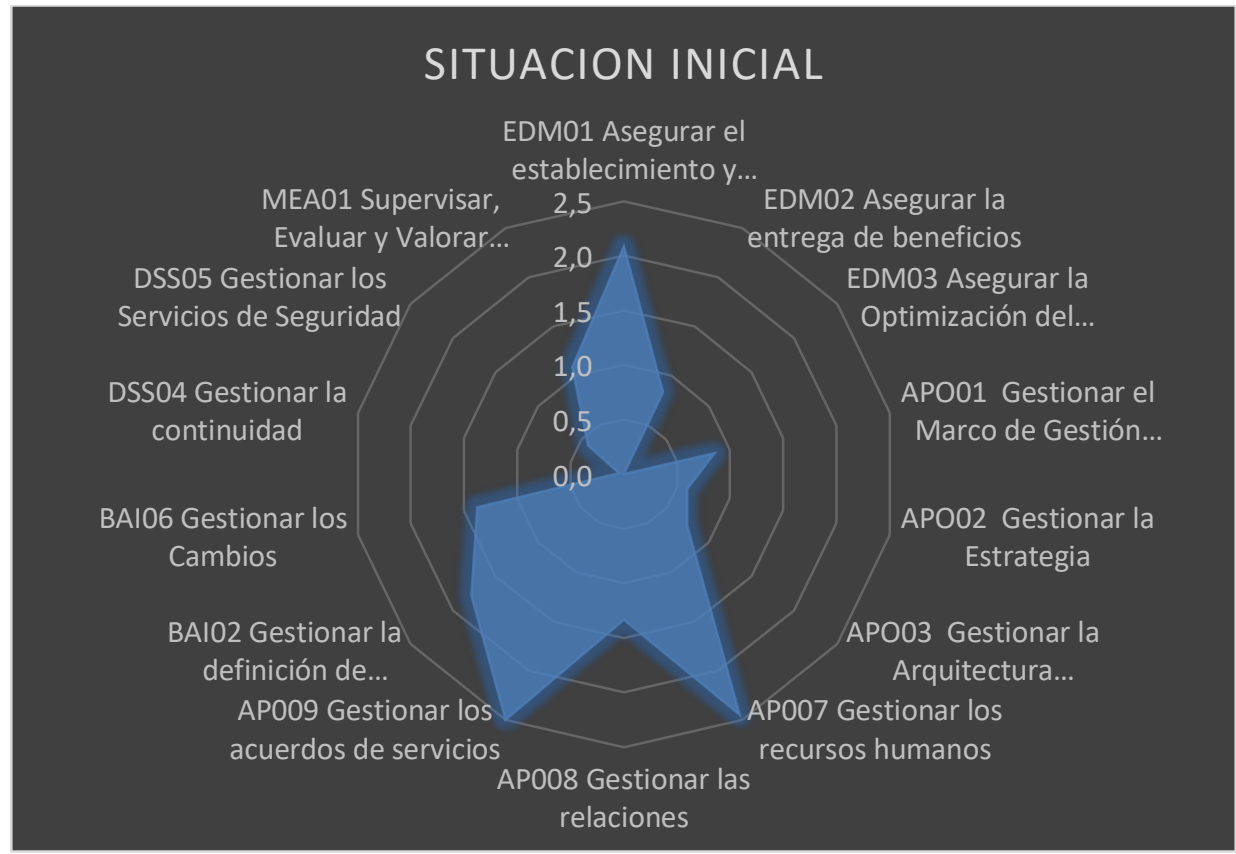

Figura 1: Se presenta la situación inicial de la UEA, determinada en la Fase 2.

Fuente: Villareal (2018)

En resumen, la UEA demuestra una madurez valorada en 1.1; ubicada en el nivel 1: Proceso ejecutado. Es decir, el proceso utilizado alcanza su propósito, pero se evidencia la existencia de problemas causados principalmente por procesos no estandarizados.

\section{Fase 3. Situación esperada}

Una de las principales metas de esta etapa es separar el gobierno de la gestión mediante la división de responsabilidades en la administración de TI (Figura 2). Para ello, se en la UEA se implementa un Comité de Estrategia de TI (dependiente del Rectorado) que maneja el Gobierno y se cambió la Unidad de Tecnologías por el Departamento de TI 
(dependiente del Vicerrectorado Administrativo), con unidades que permitirán la efectividad de la gestión (Figura 3). Con base a lo expuesto, y para el cumplimiento de las responsabilidades asignadas, se determinaron unidades de apoyo para el cumplimiento de las estrategias definidas, mismas que están al interior del Departamento de TI:

- Unidad de proyectos de TI

- Unidad de desarrollo de Software

- Unidad de seguridad y riesgo de TI

- Unidad de Infraestructura de TI y servicio a usuarios. (Villarreal, 2018)

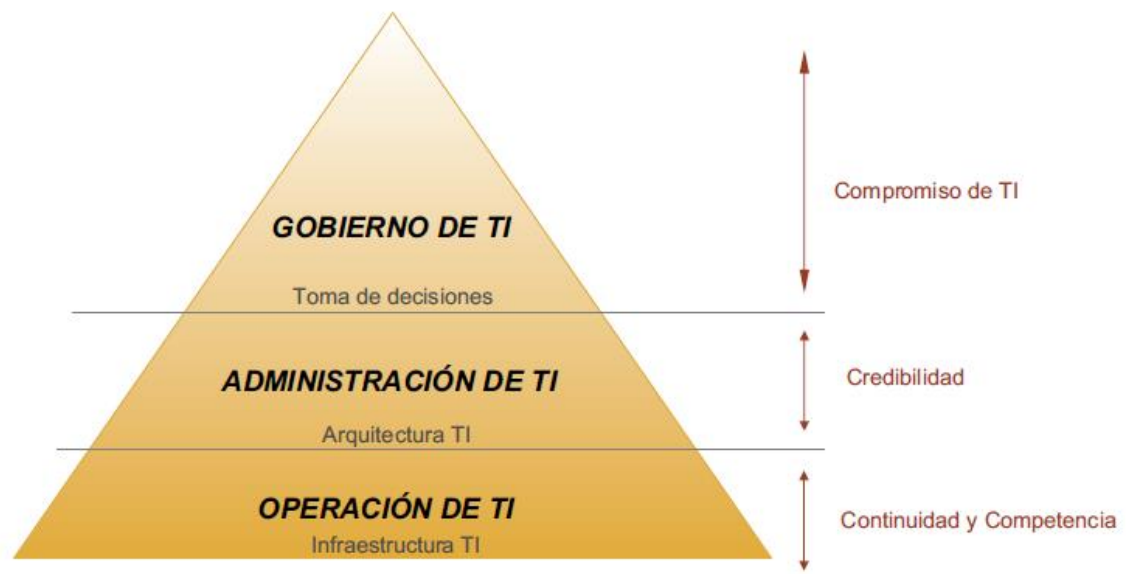

Figura 2: Se muestra la pirámide de responsabilidades de TI que guía en la estructura que debe tener el departamento de TI.

Fuente: Fernández \& Llorens (2011)

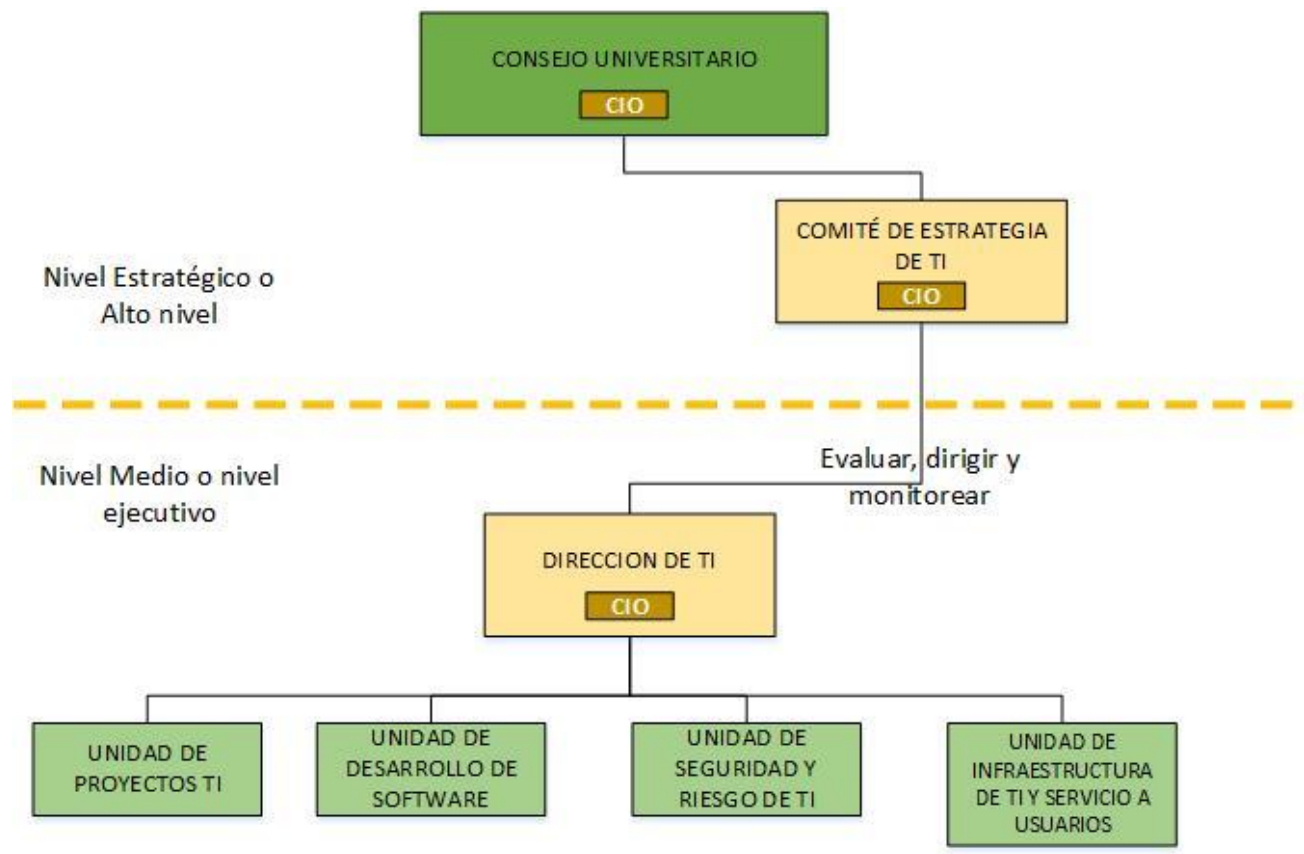

Figura 3: Se aprecia el organigrama jerárquico-funcional de la DTIC luego de la identificación de responsabilidades.

Fuente: Villarreal (2018) 


\section{Fase 4. Definición de proyectos}

Una vez identificados los procesos de gobierno y gestión de TI, éstos conducen a la identificación de las prácticas recomendadas, situación que conduce a varios procesos de mejoras y buenas prácticas identificadas (Tabla 8); los procesos identificados se encuentran adecuadamente alineados y complementados con los principios de la norma ISO 38500 (Tabla 9).

\section{Tabla 8}

Relación Proceso - Práctica Gobierno de TI

\begin{tabular}{|c|c|c|}
\hline $\mathbf{N}^{\mathbf{0}}$ & PROCESO & PRACTICA \\
\hline 1 & $\begin{array}{l}\text { EDM01.- Asegurar el } \\
\text { establecimiento y } \\
\text { mantenimiento de Marco de } \\
\text { Gobierno }\end{array}$ & $\begin{array}{l}\text { EDM01.01 Evaluar el sistema de gobierno. } \\
\text { EDM01.02 Orientar el sistema de gobierno. } \\
\text { EDM01.03 Supervisar el sistema de gobierno. }\end{array}$ \\
\hline 2 & $\begin{array}{l}\text { EDM02.- Asegurar la } \\
\text { entrega de beneficios }\end{array}$ & $\begin{array}{l}\text { EDM02.01 } \\
\text { Evaluar la optimización del valor. } \\
\text { EDM02.02 } \\
\text { Orientar la optimización del valor. } \\
\text { EDM02.03 } \\
\text { Supervisar la optimización del valor. }\end{array}$ \\
\hline 3 & $\begin{array}{l}\text { EDM03.- Asegurar la } \\
\text { Optimización del Riesgo }\end{array}$ & $\begin{array}{l}\text { EDM03.01 } \\
\text { Evaluar la gestión de riesgos. } \\
\text { EDM03.02 } \\
\text { Orientar la gestión de riesgos. } \\
\text { EDM03.03 } \\
\text { Supervisar la gestión de riesgos. }\end{array}$ \\
\hline 4 & $\begin{array}{l}\text { APO01.- Gestionar el } \\
\text { Marco de Gestión de TI }\end{array}$ & $\begin{array}{l}\text { APO01.01 } \\
\text { Definir la estructura organizativa. } \\
\text { APO01.02 } \\
\text { Establecer roles y responsabilidades. } \\
\text { APO01.03 } \\
\text { Mantener los elementos catalizadores del sistema de gestión. } \\
\text { APO01.04 } \\
\text { Comunicar los objetivos y la dirección de gestión. } \\
\text { APO01.05 } \\
\text { Optimizar la ubicación de la función de TI. } \\
\text { APO01.06 } \\
\text { Definir la propiedad de la información (datos) y del sistema. } \\
\text { APO01.07 } \\
\text { Gestionar la mejora continua de los procesos. } \\
\text { APO01.08 } \\
\text { Mantener el cumplimiento con las políticas y procedimientos. }\end{array}$ \\
\hline 5 & $\begin{array}{l}\text { APO02.- Gestionar la } \\
\text { estrategia }\end{array}$ & $\begin{array}{l}\text { APO02.01 } \\
\text { Comprender la dirección de la empresa. } \\
\text { APO02.02 } \\
\text { Evaluar el entorno, capacidades y rendimiento actuales. } \\
\text { APO02.03 } \\
\text { Definir el objetivo de las capacidades de TI. } \\
\text { APO02.04 } \\
\text { Realizar un análisis de diferencias. } \\
\text { APO02.05 } \\
\text { Definir el plan estratégico y la hoja de ruta. } \\
\text { APO02.06 } \\
\text { Comunicar la estrategia y la dirección de TI. }\end{array}$ \\
\hline
\end{tabular}




\begin{tabular}{|c|c|c|}
\hline $\mathbf{N}^{\mathbf{0}}$ & PROCESO & PRACTICA \\
\hline 6 & $\begin{array}{l}\text { APO03.- Gestionar la } \\
\text { arquitectura empresarial }\end{array}$ & $\begin{array}{l}\text { APO03.01 } \\
\text { Desarrollar la visión de la arquitectura de empresa. } \\
\text { APO03.02 } \\
\text { Definir la arquitectura de referencia. } \\
\text { APO03.03 } \\
\text { Seleccionar las oportunidades y las soluciones. } \\
\text { APO03.04 } \\
\text { Definir la implantación de la arquitectura. } \\
\text { APO03.05 } \\
\text { Proveer los servicios de arquitectura empresarial. }\end{array}$ \\
\hline 7 & $\begin{array}{l}\text { APO07.- Gestionar los } \\
\text { recursos humanos }\end{array}$ & $\begin{array}{l}\text { APO07.01 } \\
\text { Mantener la dotación de personal suficiente y adecuada. } \\
\text { APO07.02 } \\
\text { Identificar personal clave de TI. } \\
\text { APO07.03 } \\
\text { Mantener las habilidades y competencias del personal. } \\
\text { APO07.04 } \\
\text { Evaluar el desempeño laboral de los empleados. } \\
\text { APO07.05 } \\
\text { Planificar y realizar un seguimiento del uso de recursos } \\
\text { humanos de TI y del negocio. } \\
\text { APO07.06 } \\
\text { Gestionar el personal contratado. }\end{array}$ \\
\hline 8 & $\begin{array}{l}\text { APO08.- Gestionar las } \\
\text { relaciones }\end{array}$ & $\begin{array}{l}\text { APO08.01 } \\
\text { Entender las expectativas del negocio. } \\
\text { APO08.02 } \\
\text { Identificar oportunidades, riesgos y limitaciones de TI para } \\
\text { mejorar el negocio. } \\
\text { APO08.03 } \\
\text { Gestionar las relaciones con el negocio. } \\
\text { APO08.04 } \\
\text { Coordinar y comunicar. } \\
\text { APO08.05 } \\
\text { Proveer datos de entrada para la mejora continua de los } \\
\text { servicios. }\end{array}$ \\
\hline 9 & $\begin{array}{l}\text { APO09.- Gestionar los } \\
\text { acuerdos de servicios }\end{array}$ & $\begin{array}{l}\text { APO09.01 } \\
\text { Identificar servicios TI. } \\
\text { APO09.02 } \\
\text { Catalogar servicios basados en TI. } \\
\text { APO09.03 } \\
\text { Definir y preparar acuerdos de servicio. } \\
\text { APO09.04 } \\
\text { Supervisar e informar de los niveles de servicio. } \\
\text { APO09.05 } \\
\text { Revisar acuerdos de servicio y contratos. }\end{array}$ \\
\hline 10 & $\begin{array}{l}\text { BAI02.- Gestionar la } \\
\text { definición de requisitos }\end{array}$ & $\begin{array}{l}\text { BAI02.01 } \\
\text { Definir y mantener los } \\
\text { requerimientos técnicos y } \\
\text { funcionales de negocio. } \\
\text { BAI02.02 } \\
\text { Realizar un estudio de } \\
\text { viabilidad y proponer soluciones } \\
\text { alternativas. } \\
\text { BAI02.03 } \\
\text { Gestionar los riesgos de los } \\
\text { requerimientos. }\end{array}$ \\
\hline
\end{tabular}




\begin{tabular}{|c|c|c|}
\hline $\mathbf{N}^{\mathbf{0}}$ & PROCESO & PRACTICA \\
\hline & & $\begin{array}{l}\text { BAI02.04 } \\
\text { Obtener la aprobación de los } \\
\text { requerimientos y soluciones. }\end{array}$ \\
\hline 11 & $\begin{array}{l}\text { BAI06.- Gestionar los } \\
\text { Cambios }\end{array}$ & $\begin{array}{l}\text { BAI06.01 } \\
\text { Evaluar, priorizar y autorizar peticiones de cambio. } \\
\text { BAI06.02 } \\
\text { Gestionar cambios de emergencia. } \\
\text { BAI06.03 } \\
\text { Hacer seguimiento e informar de cambios de estado. } \\
\text { BAI06.04 } \\
\text { Cerrar y documentar los cambios. }\end{array}$ \\
\hline 12 & $\begin{array}{l}\text { DSS04.- Gestionar la } \\
\text { Continuidad }\end{array}$ & $\begin{array}{l}\text { DSS04.01 } \\
\text { Definir la política de continuidad del negocio, objetivos y } \\
\text { alcance. } \\
\text { DSS04.02 } \\
\text { Mantener una estrategia de continuidad. } \\
\text { DSS04.03 } \\
\text { Desarrollar e implementar una respuesta a la continuidad del } \\
\text { negocio. } \\
\text { DSS04.04 } \\
\text { Ejercitar, probar y revisar el plan de continuidad. } \\
\text { DSS04.05 } \\
\text { Revisar, mantener y mejorar el plan de continuidad. } \\
\text { DSS04.06 } \\
\text { Proporcionar formación en el plan de continuidad. } \\
\text { DSS04.07 } \\
\text { Gestionar acuerdos de respaldo. } \\
\text { DSS04.08 } \\
\text { Ejecutar revisiones post-reanudación. }\end{array}$ \\
\hline 13 & $\begin{array}{l}\text { DSS05.- Gestionar los } \\
\text { Servicios de Seguridad }\end{array}$ & $\begin{array}{l}\text { DSS05.01 } \\
\text { Proteger contra software malicioso (malware). } \\
\text { DSS05.02 } \\
\text { Gestionar la seguridad de la red y las conexiones. } \\
\text { DSS05.03 } \\
\text { Gestionar la seguridad de los puestos de usuario final. } \\
\text { DSS05.04 } \\
\text { Gestionar la identidad del usuario y el acceso lógico. } \\
\text { DSS05.05 } \\
\text { Gestionar el acceso físico a los activos de TI. } \\
\text { DSS05.06 } \\
\text { Gestionar documentos sensibles y dispositivos de salida. } \\
\text { DSS05.07 } \\
\text { Supervisar la infraestructura para detectar eventos } \\
\text { relacionados con la seguridad. }\end{array}$ \\
\hline 14 & $\begin{array}{l}\text { MEA01.- Supervisar, } \\
\text { Evaluar y Valorar } \\
\text { Rendimiento y Conformidad }\end{array}$ & $\begin{array}{l}\text { MEA01.01 } \\
\text { Establecer un enfoque de la supervisión. } \\
\text { MEA01.02 } \\
\text { Establecer los objetivos de cumplimiento y rendimiento. } \\
\text { MEA01.03 } \\
\text { Recopilar y procesar los datos de cumplimiento y } \\
\text { rendimiento. } \\
\text { MEA01.04 } \\
\text { Analizar e informar sobre el rendimiento. } \\
\text { MEA01.05 } \\
\text { Asegurar la implantación de medidas correctivas. }\end{array}$ \\
\hline
\end{tabular}

Fuente: Villarreal (2018) 


\section{Tabla 9}

Alineamiento de COBIT e ISO 38500

\begin{tabular}{|c|c|c|}
\hline $\begin{array}{l}\text { PRINCIPIOS } \\
\text { ISO } 38500\end{array}$ & PROCESO & CATALIZADORES COBIT 5 \\
\hline Responsabilidad & $\begin{array}{l}\text { EDM01.- Asegurar el establecimiento y } \\
\text { mantenimiento de Marco de Gobierno } \\
\text { APO01.- Gestionar el Marco de Gestión } \\
\text { de TI } \\
\text { MEA01.- Supervisar, Evaluar y Valorar } \\
\text { Rendimiento y Conformidad }\end{array}$ & Estructuras organizativas \\
\hline Estrategia & $\begin{array}{l}\text { EDM02.- Asegurar la entrega de } \\
\text { beneficios } \\
\text { EDM03.- Asegurar la Optimización del } \\
\text { Riesgo } \\
\text { APO02.- Gestionar la estrategia } \\
\text { APO08.- Gestionar las relaciones } \\
\text { BAI02.- Gestionar la definición de } \\
\text { requisitos } \\
\text { BAI06.- Gestionar los Cambios } \\
\text { DSS04.- Gestionar la Continuidad }\end{array}$ & Proceso \\
\hline Adquisición & APO02.- Gestionar la estrategia & $\begin{array}{l}\text { Proceso; información; servicios, } \\
\text { infraestructura y aplicaciones. }\end{array}$ \\
\hline Desempeño & $\begin{array}{l}\text { APO03.- Gestionar la arquitectura } \\
\text { empresarial } \\
\text { APO09.- Gestionar los acuerdos de } \\
\text { servicios } \\
\text { DSS05.- Gestionar los Servicios de } \\
\text { Seguridad }\end{array}$ & Procesos; estructuras organizativas. \\
\hline Cumplimiento & $\begin{array}{l}\text { APO02.- Gestionar la estrategia } \\
\text { MEA01.- Supervisar, Evaluar y Valorar } \\
\text { Rendimiento y Conformidad }\end{array}$ & $\begin{array}{l}\text { Información; estructuras organizativas; } \\
\text { procesos; servicios, infraestructura y } \\
\text { aplicaciones. }\end{array}$ \\
\hline $\begin{array}{l}\text { Comportamiento } \\
\text { Humano }\end{array}$ & $\begin{array}{l}\text { APO07.- Gestionar los recursos } \\
\text { humanos } \\
\text { BAI02.- Gestionar la definición de } \\
\text { requisitos }\end{array}$ & $\begin{array}{l}\text { Personas, habilidades y competencias; } \\
\text { cultura, ética y comportamiento. }\end{array}$ \\
\hline
\end{tabular}

Fuente: Villarreal (2018)

\section{Fase 5. Definición de métricas}

La evaluación de los procesos realizados por el gobierno de TI es altamente necesaria, por ello y siguiendo la metodología se definieron métricas (Tabla 10) que permiten identificar puntos débiles especialmente en prestación de servicios. Dichas métricas están de acuerdo con los procesos definidos y son seleccionadas de los procesos catalizadores de ISACA (2012). (Villarreal, 2018). 


\section{Tabla 10}

Métricas de Gobierno de TI

\begin{tabular}{|c|c|c|c|}
\hline & PROCESO & META DEL PROCESO & METRICA \\
\hline \multirow{3}{*}{ EDM01 } & \multirow{3}{*}{$\begin{array}{l}\text { Asegurar el } \\
\text { establecimiento } \\
\text { y mantenimiento } \\
\text { de Marco de } \\
\text { Gobierno }\end{array}$} & $\begin{array}{l}\text { Modelo estratégico de toma de } \\
\text { decisiones para que las TI sean } \\
\text { efectivas y estén alineadas con el } \\
\text { entorno externo e interno de la } \\
\text { empresa y los requerimientos de las } \\
\text { partes interesadas. }\end{array}$ & $\begin{array}{l}\text { Nivel de satisfacción mediante } \\
\text { encuestas de las personas interesadas }\end{array}$ \\
\hline & & $\begin{array}{l}\text { Garantizar que el sistema de gobierno } \\
\text { para TI está incorporado al gobierno } \\
\text { corporativo. }\end{array}$ & $\begin{array}{l}\text { Número de roles, responsabilidades } \\
\text { y autoridades que están definidas, } \\
\text { asignadas y aceptadas a gestores } \\
\text { para una gestión del negocio y de las } \\
\text { TI apropiados. }\end{array}$ \\
\hline & & $\begin{array}{l}\text { Obtener garantías de que el sistema } \\
\text { de gobierno para TI está operando de } \\
\text { manera efectiva. }\end{array}$ & $\begin{array}{l}\text { Frecuencia del reporte del gobierno } \\
\text { de TI al Consejo universitario y/o a } \\
\text { Rectorado }\end{array}$ \\
\hline \multirow{3}{*}{ EDM02 } & \multirow{3}{*}{$\begin{array}{l}\text { Asegurar la } \\
\text { entrega de } \\
\text { beneficios }\end{array}$} & $\begin{array}{l}\text { La empresa está asegurando un valor } \\
\text { óptimo de su portafolio de iniciativas } \\
\text { TI, servicios y activos aprobados. }\end{array}$ & $\begin{array}{l}\text { Nivel de satisfacción de las partes } \\
\text { interesadas con la habilidad de la } \\
\text { empresa para obtener valor de las } \\
\text { iniciativas TI }\end{array}$ \\
\hline & & $\begin{array}{l}\text { Se deriva un valor óptimo de la } \\
\text { inversión TI mediante prácticas de } \\
\text { gestión del valor en la empresa. }\end{array}$ & $\begin{array}{l}\text { Porcentaje de iniciativas TI en el } \\
\text { portafolio general en las que el valor } \\
\text { está siendo gestionado a través del } \\
\text { ciclo de vida completo }\end{array}$ \\
\hline & & $\begin{array}{l}\text { Las inversiones individuales en TI } \\
\text { contribuyen a un valor óptimo. }\end{array}$ & $\begin{array}{l}\text { Porcentaje del valor TI esperado } \\
\text { realizado }\end{array}$ \\
\hline \multirow{3}{*}{ EDM03 } & \multirow{3}{*}{$\begin{array}{l}\text { Asegurar la } \\
\text { Optimización } \\
\text { del Riesgo }\end{array}$} & $\begin{array}{l}\text { Los umbrales de riesgo son definidos } \\
\text { y comunicados y los riesgos clave } \\
\text { relacionados con la TI son conocidos. }\end{array}$ & $\begin{array}{l}\text { Número de potenciales riesgos TI } \\
\text { identificados y gestionados }\end{array}$ \\
\hline & & $\begin{array}{l}\text { La empresa gestiona el riesgo crítico } \\
\text { empresarial relacionado con las TI } \\
\text { eficaz y eficientemente. }\end{array}$ & $\begin{array}{l}\text { Porcentaje de proyectos de la } \\
\text { empresa que consideran el riesgo TI }\end{array}$ \\
\hline & & $\begin{array}{l}\text { Los riesgos empresariales } \\
\text { relacionados con las TI no exceden el } \\
\text { apetito de riesgo y el impacto del } \\
\text { riesgo TI en el valor de la empresa es } \\
\text { identificado y gestionado. }\end{array}$ & $\begin{array}{l}\text { *Porcentaje de riesgos TI que } \\
\text { exceden el riesgo empresarial } \\
\text { tolerado }\end{array}$ \\
\hline \multirow{2}{*}{ APO01 } & \multirow{2}{*}{$\begin{array}{l}\text { Gestionar el } \\
\text { Marco de } \\
\text { Gestión de TI }\end{array}$} & $\begin{array}{l}\text { Se ha definido y se mantiene un } \\
\text { conjunto eficaz de políticas. }\end{array}$ & $\begin{array}{l}\text { Porcentaje de políticas, estándares y } \\
\text { otros elementos catalizadores activos } \\
\text { documentados y actualizados }\end{array}$ \\
\hline & & $\begin{array}{l}\text { Todos tienen conocimiento de las } \\
\text { políticas y de cómo deberían } \\
\text { implementarse. }\end{array}$ & $\begin{array}{l}\text { Número de empleados que asistieron } \\
\text { a sesiones de formación o de } \\
\text { sensibilización }\end{array}$ \\
\hline \multirow{2}{*}{ APO02 } & \multirow{2}{*}{$\begin{array}{l}\text { Gestionar la } \\
\text { Estrategia }\end{array}$} & $\begin{array}{l}\text { Todos los aspectos de la estrategia de } \\
\text { TI están alineados con la estrategia } \\
\text { del negocio. }\end{array}$ & $\begin{array}{l}\text { Porcentaje de los objetivos del } \\
\text { negocio considerados en la estrategia } \\
\text { de TI }\end{array}$ \\
\hline & & $\begin{array}{l}\text { La estrategia de TI es coste-efectiva, } \\
\text { apropiada, realista, factible, enfocada } \\
\text { al negocio y equilibrada. }\end{array}$ & $\begin{array}{l}\text { Porcentaje de iniciativas en la } \\
\text { estrategia de TI autofinanciadas (los } \\
\text { beneficios superan los costes) }\end{array}$ \\
\hline
\end{tabular}




\begin{tabular}{|c|c|c|c|}
\hline & PROCESO & META DEL PROCESO & METRICA \\
\hline & & $\begin{array}{l}\text { Se pueden derivar objetivos a corto } \\
\text { plazo claros, concretos, y trazables de } \\
\text { iniciativas a largo plazo específicas, } \\
\text { y se pueden traducir, por tanto, en } \\
\text { planes operativos. }\end{array}$ & $\begin{array}{l}\text { Porcentaje de proyectos en la cartera } \\
\text { de proyectos de TI que pueden ser } \\
\text { directamente trazables con la } \\
\text { estrategia de TI }\end{array}$ \\
\hline & & $\begin{array}{l}\text { TI es un generador de valor para el } \\
\text { negocio. }\end{array}$ & $\begin{array}{l}\text { Porcentaje de proyectos/iniciativas } \\
\text { de TI respaldados directamente por } \\
\text { los propietarios del negocio }\end{array}$ \\
\hline & & $\begin{array}{l}\text { Existe conciencia de la estrategia de } \\
\text { TI y una clara asignación de } \\
\text { responsabilidades para su entrega. }\end{array}$ & $\begin{array}{l}\text { Porcentaje de iniciativas estratégicas } \\
\text { con asignación de responsabilidades }\end{array}$ \\
\hline \multirow{4}{*}{ APO03 } & \multirow{4}{*}{$\begin{array}{l}\text { Gestionar la } \\
\text { Arquitectura } \\
\text { Empresarial }\end{array}$} & $\begin{array}{l}\text { La arquitectura y los estándares son } \\
\text { eficaces apoyando a la empresa. }\end{array}$ & $\begin{array}{l}\text { Beneficios aportados por el proyecto } \\
\text { que pueden ser trazados a la } \\
\text { implicación de la arquitectura (por } \\
\text { ejemplo, reducción de costes debido } \\
\text { a la reutilización) }\end{array}$ \\
\hline & & $\begin{array}{l}\text { La cartera de servicios de la } \\
\text { arquitectura de empresa soporta el } \\
\text { cambio empresarial ágil. }\end{array}$ & $\begin{array}{l}\text { Porcentaje de proyectos que usan los } \\
\text { servicios de la arquitectura de } \\
\text { empresa }\end{array}$ \\
\hline & & $\begin{array}{l}\text { Existen dominios apropiados y } \\
\text { actualizados y/o arquitecturas } \\
\text { federadas que proveen información } \\
\text { fiable de la arquitectura. }\end{array}$ & $\begin{array}{l}\text { Fecha de la última actualización en } \\
\text { el dominio y/o arquitecturas } \\
\text { federadas. }\end{array}$ \\
\hline & & $\begin{array}{l}\text { Se utiliza un marco de arquitectura } \\
\text { de empresa y una metodología } \\
\text { común, así como un repositorio de } \\
\text { arquitectura integrado, con el fin de } \\
\text { permitir la reutilización de } \\
\text { eficiencias dentro de la empresa. }\end{array}$ & $\begin{array}{l}\text { Porcentaje de proyectos que utilizan } \\
\text { el marco de trabajo y la metodología } \\
\text { para reutilizar componentes ya } \\
\text { definidos. }\end{array}$ \\
\hline \multirow[t]{2}{*}{ AP007 } & \multirow{2}{*}{$\begin{array}{l}\text { Gestionar los } \\
\text { recursos } \\
\text { humanos }\end{array}$} & $\begin{array}{l}\text { La estructura organizacional y las } \\
\text { relaciones de TI son flexibles y dan } \\
\text { respuesta ágil. }\end{array}$ & $\begin{array}{l}\text { Número de definiciones de servicio } \\
\text { y catálogos de servicio }\end{array}$ \\
\hline & & $\begin{array}{l}\text { Los recursos humanos son } \\
\text { gestionados eficaz y eficientemente. }\end{array}$ & Evaluación de desempeño \\
\hline \multirow{3}{*}{ AP008 } & \multirow{3}{*}{$\begin{array}{l}\text { Gestionar las } \\
\text { relaciones }\end{array}$} & $\begin{array}{l}\text { Las estrategias, planes y requisitos de } \\
\text { negocio están bien entendidos, } \\
\text { documentados y aprobados. }\end{array}$ & $\begin{array}{l}\text { Porcentaje de servicios TI alineados } \\
\text { con los requisitos del negocio. }\end{array}$ \\
\hline & & $\begin{array}{l}\text { Existencia de buenas relaciones entre } \\
\text { la empresa y las TI. }\end{array}$ & $\begin{array}{l}\text { Resultados de las encuestas de } \\
\text { satisfacción de los usuarios } \\
\text { y del personal de TI. }\end{array}$ \\
\hline & & $\begin{array}{l}\text { Las partes interesadas del negocio } \\
\text { son conscientes de las oportunidades } \\
\text { posibilitadas por la TI. }\end{array}$ & $\begin{array}{l}\text { Encuesta del nivel de concienciación } \\
\text { tecnológica de las partes } \\
\text { interesadas de negocio. }\end{array}$ \\
\hline \multirow{3}{*}{ AP009 } & \multirow{3}{*}{$\begin{array}{l}\text { Gestionar los } \\
\text { acuerdos de } \\
\text { servicios }\end{array}$} & $\begin{array}{l}\text { La empresa puede usar de modo } \\
\text { efectivo los servicios TI tal como se } \\
\text { han definido en el catálogo. }\end{array}$ & $\begin{array}{l}\text { Número de procesos de negocio con } \\
\text { acuerdos de servicio definidos }\end{array}$ \\
\hline & & $\begin{array}{l}\text { Los acuerdos de servicio reflejan las } \\
\text { capacidades y necesidades de la TI }\end{array}$ & $\begin{array}{l}\text { Porcentaje de servicio TI activos } \\
\text { cubiertos por acuerdos de servicio }\end{array}$ \\
\hline & & $\begin{array}{l}\text { Los servicios TI rinden como está } \\
\text { estipulado en los acuerdos de } \\
\text { servicio. }\end{array}$ & $\begin{array}{l}\text { Porcentaje de servicios } \\
\text { monitorizados para cumplir los } \\
\text { acuerdos }\end{array}$ \\
\hline
\end{tabular}




\begin{tabular}{|c|c|c|c|}
\hline & PROCESO & META DEL PROCESO & METRICA \\
\hline \multirow{4}{*}{ BAI02 } & \multirow{4}{*}{$\begin{array}{l}\text { Gestionar la } \\
\text { definición de } \\
\text { requisitos }\end{array}$} & $\begin{array}{l}\text { Los requerimientos funcionales y } \\
\text { técnicos del negocio reflejan las } \\
\text { necesidades y expectativas de la } \\
\text { organización. }\end{array}$ & $\begin{array}{l}\text { Nivel de satisfacción de las partes } \\
\text { interesadas con los requerimientos }\end{array}$ \\
\hline & & $\begin{array}{l}\text { La solución propuesta satisface los } \\
\text { requerimientos funcionales, técnicos } \\
\text { y de cumplimiento del negocio. }\end{array}$ & $\begin{array}{l}\text { Porcentaje de requerimientos } \\
\text { satisfechos por la solución propuesta }\end{array}$ \\
\hline & & $\begin{array}{l}\text { El riesgo asociado con los } \\
\text { requerimientos ha sido tomado en } \\
\text { cuenta en la solución propuesta. }\end{array}$ & $\begin{array}{l}\text { Porcentaje de riesgos no mitigado } \\
\text { exitosamente }\end{array}$ \\
\hline & & $\begin{array}{l}\text { Los requerimientos y soluciones } \\
\text { propuestas cumplen con los objetivos } \\
\text { del caso de negocio (valor esperado y } \\
\text { costes probables). }\end{array}$ & $\begin{array}{l}\text { Porcentaje de los objetivos del caso } \\
\text { de negocio alcanzados por la } \\
\text { solución propuesta }\end{array}$ \\
\hline \multirow{4}{*}{ BAI06 } & \multirow{4}{*}{$\begin{array}{c}\text { Gestionar los } \\
\text { Cambios }\end{array}$} & $\begin{array}{l}\text { Los cambios autorizados son } \\
\text { realizados de acuerdo a sus } \\
\text { cronogramas respectivos y con } \\
\text { errores mínimos. }\end{array}$ & $\begin{array}{l}\text { Reducción en el tiempo y esfuerzo } \\
\text { necesarios para aplicar los cambios }\end{array}$ \\
\hline & & $\begin{array}{l}\text { Las evaluaciones de impacto revelan } \\
\text { el efecto de los cambios sobre todos } \\
\text { los componentes afectados. }\end{array}$ & $\begin{array}{l}\text { Porcentaje de cambios con éxito } \\
\text { debidos a evaluaciones de impacto } \\
\text { adecuadas }\end{array}$ \\
\hline & & $\begin{array}{l}\text { Todos los cambios de emergencia } \\
\text { son revisados y autorizados una vez } \\
\text { hecho el cambio. }\end{array}$ & $\begin{array}{l}\text { Número de cambios de emergencia } \\
\text { no autorizados una vez hecho el } \\
\text { cambio identificados }\end{array}$ \\
\hline & & $\begin{array}{l}\text { Las principales partes interesadas } \\
\text { están informadas sobre todos los } \\
\text { aspectos del cambio. }\end{array}$ & $\begin{array}{l}\text { Porcentaje de satisfacción de las } \\
\text { partes interesadas con las } \\
\text { comunicaciones de los cambios }\end{array}$ \\
\hline \multirow{4}{*}{ DSS04 } & \multirow{4}{*}{$\begin{array}{l}\text { Gestionar la } \\
\text { continuidad }\end{array}$} & $\begin{array}{l}\text { La información crítica para el } \\
\text { negocio está disponible para el } \\
\text { negocio en línea con los niveles de } \\
\text { servicio mínimos requeridos }\end{array}$ & $\begin{array}{l}\text { Porcentaje de medios de respaldo } \\
\text { transferidos y almacenados de forma } \\
\text { segura }\end{array}$ \\
\hline & & $\begin{array}{l}\text { Las pruebas de continuidad del } \\
\text { servicio han verificado la efectividad } \\
\text { del plan. }\end{array}$ & Frecuencia de las pruebas \\
\hline & & $\begin{array}{l}\text { Un plan de continuidad actualizado } \\
\text { refleja los requisitos de negocio } \\
\text { actuales. }\end{array}$ & $\begin{array}{l}\text { Porcentaje de mejoras acordadas que } \\
\text { han sido reflejadas en el plan }\end{array}$ \\
\hline & & $\begin{array}{l}\text { Las partes interesadas internas y } \\
\text { externas han sido formadas en el plan } \\
\text { de continuidad. }\end{array}$ & $\begin{array}{l}\text { Porcentaje de interesados internos y } \\
\text { externos que han recibido formación }\end{array}$ \\
\hline \multirow{3}{*}{ DSS05 } & \multirow{3}{*}{$\begin{array}{c}\text { Gestionar los } \\
\text { Servicios de } \\
\text { Seguridad }\end{array}$} & $\begin{array}{l}\text { La seguridad de las redes y las } \\
\text { comunicaciones cumple con las } \\
\text { necesidades del negocio. }\end{array}$ & $\begin{array}{l}\text { Número de vulnerabilidades } \\
\text { descubiertas } \\
\text { Número de rupturas (breaches) de } \\
\text { cortafuegos }\end{array}$ \\
\hline & & $\begin{array}{l}\text { La información procesada, } \\
\text { almacenada y transmitida en los } \\
\text { dispositivos } \\
\text { de usuario final está protegida. }\end{array}$ & $\begin{array}{l}\text { Porcentaje de individuos que reciben } \\
\text { formación de concienciación } \\
\text { relativa al uso de dispositivos de } \\
\text { usuario final }\end{array}$ \\
\hline & & $\begin{array}{l}\text { Todos los usuarios están } \\
\text { identificados de manera única y } \\
\text { tienen derechos de acceso de acuerdo } \\
\text { con sus roles en el negocio. }\end{array}$ & $\begin{array}{l}\text { Número de cuentas (con respecto al } \\
\text { número de usuarios/empleados } \\
\text { autorizados) }\end{array}$ \\
\hline
\end{tabular}




\begin{tabular}{|c|c|c|c|}
\hline & PROCESO & META DEL PROCESO & METRICA \\
\hline & & $\begin{array}{l}\text { Se han implantado medidas físicas } \\
\text { para proteger la información de } \\
\text { accesos no autorizados, daños e } \\
\text { interferencias mientras es procesada, } \\
\text { almacenada o transmitida. }\end{array}$ & $\begin{array}{l}\text { Porcentaje de pruebas periódicas de } \\
\text { los dispositivos de seguridad del } \\
\text { entorno }\end{array}$ \\
\hline & & $\begin{array}{l}\text { La información electrónica tiene las } \\
\text { medidas de seguridad apropiadas } \\
\text { mientras está almacenada, } \\
\text { transmitida o destruida. }\end{array}$ & $\begin{array}{l}\text { Políticas de seguridad para evitar } \\
\text { incidentes relacionados con accesos } \\
\text { no autorizados a la información. }\end{array}$ \\
\hline \multirow{5}{*}{ MEA01 } & \multirow{5}{*}{$\begin{array}{l}\text { Supervisar, } \\
\text { Evaluar y } \\
\text { Valorar } \\
\text { Rendimiento y } \\
\text { Conformidad }\end{array}$} & $\begin{array}{l}\text { Objetivos y métricas aprobadas por } \\
\text { las partes interesadas. }\end{array}$ & $\begin{array}{l}\text { Porcentaje de informes de } \\
\text { rendimiento entregados en plazo }\end{array}$ \\
\hline & & $\begin{array}{l}\text { Procesos medidos acorde a las } \\
\text { métricas y objetivos acordados. }\end{array}$ & $\begin{array}{l}\text { Porcentaje de procesos con objetivos } \\
\text { y métricas definidas. }\end{array}$ \\
\hline & & $\begin{array}{l}\text { La monitorización, evaluación y } \\
\text { generación de información es } \\
\text { efectiva y } \\
\text { operativa. }\end{array}$ & $\begin{array}{l}\text { Porcentaje de procesos críticos } \\
\text { supervisados }\end{array}$ \\
\hline & & $\begin{array}{l}\text { Objetivos y métricas integradas } \\
\text { dentro de los sistemas de supervisión } \\
\text { de la empresa. }\end{array}$ & $\begin{array}{l}\text { Porcentaje de objetivos y métricas } \\
\text { alineadas al sistema de supervisión } \\
\text { de la empresa }\end{array}$ \\
\hline & & $\begin{array}{l}\text { Los informes acerca del rendimiento } \\
\text { y conformidad de los procesos son } \\
\text { útiles y a tiempo. }\end{array}$ & $\begin{array}{l}\text { Porcentaje de informes de } \\
\text { rendimiento entregados en plazo }\end{array}$ \\
\hline
\end{tabular}

Fuente: Villarreal (2018)

\section{Fase 6. Supervisión de beneficios}

La supervisión de beneficios está a cargo del director de TI y para ello se implementó una aplicación de gestión de cartera de proyectos, desde el cual se realiza el monitoreo de los proyectos que se desarrollan dentro de las diferentes áreas del DTIC. Como complemento, se desarrolló además otra aplicación para la evaluación y monitoreo de procesos y recursos, mismo que permite realizar analítica de datos para facilitar a las autoridades de la UEA y responsables de TI la toma de decisiones. (Villarreal, 2018).

\section{Fase 7. Monitorear y evaluar procesos de TI}

Luego evaluar los procesos identificados y aplicados en la UEA, se procedió con la identificación de los procesos que no lograron alcanzar su objetivo (Tabla 11), mismos que serán considerados para reestructurarlos en el próximo ciclo de vida como procesos de mejora continua. (Villarreal, 2018).

\section{Tabla 11}

Procesos para mejora

\begin{tabular}{|c|c|l|}
\hline & PROCESO & \multicolumn{1}{c|}{ METAS } \\
\hline EDM03 & $\begin{array}{c}\text { Asegurar la } \\
\text { Optimización del Riesgo }\end{array}$ & $\begin{array}{l}\text { Los umbrales de riesgo son definidos y comunicados } \\
\text { y los riesgos clave relacionados con la TI son } \\
\text { conocidos. }\end{array}$ \\
\hline
\end{tabular}




\begin{tabular}{|c|c|c|}
\hline & PROCESO & METAS \\
\hline & & $\begin{array}{l}\text { La empresa gestiona el riesgo crítico empresarial } \\
\text { relacionado con las TI eficaz y eficientemente. }\end{array}$ \\
\hline & & $\begin{array}{l}\text { Los riesgos empresariales relacionados con las TI no } \\
\text { exceden el apetito de riesgo y el impacto del riesgo } \\
\text { TI en el valor de la empresa es identificado y } \\
\text { gestionado. }\end{array}$ \\
\hline \multirow{2}{*}{ APO01 } & \multirow{2}{*}{$\begin{array}{l}\text { Gestionar el Marco de } \\
\text { Gestión de TI }\end{array}$} & $\begin{array}{l}\text { Se ha definido y se mantiene un conjunto eficaz de } \\
\text { políticas. }\end{array}$ \\
\hline & & $\begin{array}{l}\text { Todos tienen conocimiento de las políticas y de cómo } \\
\text { deberían implementarse. }\end{array}$ \\
\hline \multirow{4}{*}{ BAI06 } & \multirow{4}{*}{ Gestionar los Cambios } & $\begin{array}{l}\text { Los cambios autorizados son realizados de acuerdo a } \\
\text { sus cronogramas respectivos y con errores mínimos. }\end{array}$ \\
\hline & & $\begin{array}{l}\text { Las evaluaciones de impacto revelan el efecto de los } \\
\text { cambios sobre todos los componentes afectados. }\end{array}$ \\
\hline & & $\begin{array}{l}\text { Todos los cambios de emergencia son revisados y } \\
\text { autorizados una vez hecho el cambio. }\end{array}$ \\
\hline & & $\begin{array}{l}\text { Las principales partes interesadas están informadas } \\
\text { sobre todos los aspectos del cambio. }\end{array}$ \\
\hline \multirow{4}{*}{ DSS04 } & \multirow{4}{*}{ Gestionar la continuidad } & $\begin{array}{l}\text { La información crítica para el negocio está disponible } \\
\text { para el negocio en línea con los niveles de servicio } \\
\text { mínimos requeridos }\end{array}$ \\
\hline & & $\begin{array}{l}\text { Las pruebas de continuidad del servicio han verificado } \\
\text { la efectividad del plan. }\end{array}$ \\
\hline & & $\begin{array}{l}\text { Un plan de continuidad actualizado refleja los } \\
\text { requisitos de negocio actuales. }\end{array}$ \\
\hline & & $\begin{array}{l}\text { Las partes interesadas internas y externas han sido } \\
\text { formadas en el plan de continuidad. }\end{array}$ \\
\hline
\end{tabular}

Fuente: Villarreal (2018)

\section{Resultados y Discusión}

La UEA inició un nuevo camino hacia el Gobierno y Gestión de TI a través del alineamiento de objetivos institucionales con las estrategias de TI y la definición de responsables de la planificación estratégica, toma de decisiones y de la explotación de las TI. Se establecieron políticas que permiten una adecuada administración de recursos, gestionar riesgos y brindar seguridad a la información sensible de la institución, las mencionadas políticas establecen las directrices, y parámetros a seguir en la administración de recursos TI. Se cuenta también con procesos de autoevaluación de madurez del Gobierno y Gestión de TI, dentro de la Unidad de Tecnologías, lo que permite además optimizar los recursos tecnológicos de la institución a través de la evaluación, entrega oportuna de informes y priorización de requerimientos.

Para realizar la valoración del gobierno y gestión de TI, se evaluó el cumplimiento de las métricas establecidas en los procesos catalizadores, además de la constatación y 
observación de resultados aplicados y monitoreados a través de Sistema Integrado de Tecnologías de la Información (SITIC). Dichas evidencias permiten conocer y sustentar los niveles de madurez en los cuales se encuentra la administración de TI de la UEA. Los resultados cuantitativos detallados reflejan que del nivel de madurez "inicial" con valor 1.1, se incrementa a un nivel de madurez 3 "proceso definido", con un promedio obtenido de 3.3 (Figura 4), el cual evidencia que se han estandarizado, documentado y comunicado los procedimientos mediante formación. Los procedimientos no son sofisticados en sí mismos, pero sí la formalización de las prácticas existentes; con este cambio se plantea que las próximas metas y objetivos sean orientados a incrementar el nivel de madurez del gobierno y gestión de TI.

Por otra parte la identificación de lineamientos claros de gestión y gobierno de TI se garantizó con base a la aplicación de la técnica de cascada, de la cual se obtuvieron tres objetivos de TI y catorce procesos catalizadores plasmados en el nuevo Plan Operativo Anual del Área de Tecnologías; mismos que brindan soporte tecnológico para el alcance de los objetivos institucionales, todo esto junto a la adaptabilidad entre COBIT 5 e ISO 38500 para construir el procedimiento de implementación del modelo de gestión y gobierno de TI en la UEA.

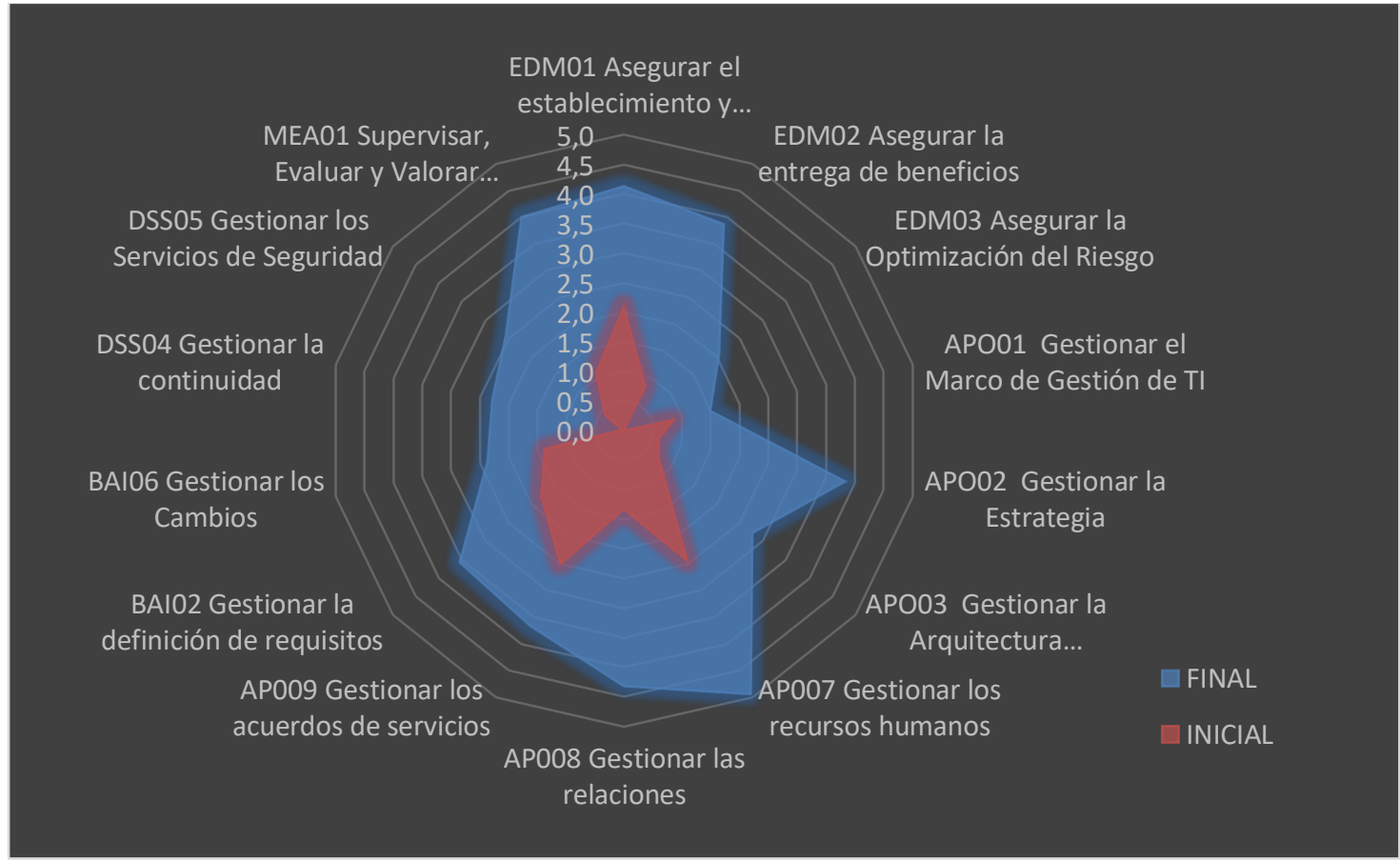

Figura 4: Se visualizan gráficamente los estados inicial y final; se puede determinar la mejora que tuvieron los procesos de gobierno y gestión luego de la implementación del modelo.

La información recabada sobre el marco de referencia de gobierno de TI para Universidades aplicado por la CRUE, permitió enfocar el uso de COBIT 5 e ISO 35800 para la aplicación en las universidades, de manera exclusiva para el dominio de la UEA, ya que coinciden con los principios de buenas prácticas y actividades enfocadas en alinear los objetivos institucionales con las estrategias de TI. Esto permitió evaluar opciones estratégicas, proporcionar dirección a las TI y supervisar resultados, propiciando la aproximación a la implementación de estándares ISO dentro de la universidad, situación que 
coincide con los resultados del trabajo presentado por Fernández \& Llorens (2011) para la universidad española.

La implementación del modelo de gestión y gobierno de TI permite a la UEA sostener sus procesos con el uso de tecnologías, alineando sus ejes de desarrollo con las metas de TI; añadiendo así políticas, normas y estándares a cumplir, que permitan el óptimo manejo de recursos, que resulten en la entrega de valor y satisfacción de necesidades evidenciadas a través de la medición de desempeño, fomentando un trabajo colaborativo, en busca de una mejora continua y competitividad de la institución. Para ello, se cuenta con el eficiente apoyo de la alta dirección mismo que junto con mecanismos de evaluación permitirán mejorar el desempeño y la calidad de los servicios académicos para satisfacción no sólo de los colaboradores de la institución sino también de los estudiantes, situación que coincide con lo recomendado por Valverde, Mejía \& Meza (2017).

\section{Conclusiones}

La aplicación del modelo de gobierno de TI permitió el alineamiento estratégico de las metas de TI con los objetivos de la institución, lo que condujo a la optimización de recursos y disminución de riesgos, permitiendo la asignación de responsabilidades y la toma de decisiones, a nivel gerencial y en las principales áreas de TI. Con la creación de áreas específicas de Gestión de la UEA, se pudieron identificar las metas y procesos en las dependencias restantes, lo que permite obtener mayores beneficios, y proporcionar el mejor uso de la tecnología al interior de las estructuras organizativas. El modelo de gobierno de TI aplicado, por ser adaptable a cualquier organización, permitió generar valor en los procesos institucionales gracias al uso eficiente de las tecnologías. Es así como se contribuyó a la alineación de la TI con los objetivos institucionales demostrando el alto valor que ésta proporciona a las universidades. Este trabajo contribuye al estado del arte y a la aplicación de los marcos de trabajo aquí utilizados para la determinación de necesidades y la implementación de gobiernos de TI, ya que los resultados obtenidos han demostrado los beneficios que las instituciones de educación superior pueden obtener.

\section{Bibliografía}

Ballester M. (2010) Gobierno de las TIC ISO/IEC 38500. ISACA Journal, pp. 1-4.

Camino J. (2017) "Diseño de una solución para la gestión de los procesos de incidencia y Help Desk alineados a Itil y Cobit". Caso de uso empresa Sifuturo SA. Pontificia Universidad Católica del Ecuador. Quito, Ecuador.

Changmarín C. (2018) "Gobierno Corporativo: Efecto del Comité de Auditoría y la Información en la competitividad para la PYME". Revista Contabilidad y Auditoría. No. 48. p. 51-94. ISSN 1515-2340. eISSN 1852-446X.

Chinkes E. (2015) Las Tecnologías de la Información y la Comunicación Potenciando la Universidad del Siglo XXI. RedCLARA.

Coba E., Díaz J. Altamirano M. (2018) "Impacto del gobierno corporativo en las asociaciones de la economía social y solidaria en Tungurahua-Ecuador”. Revista Actualidad Contable Faces. Vol. 21, no 37, p. 24-58. ISSN: 1316-8533. eISSN: 2244-8772 
Enriquez R., Valverde F., Llorens F. (2017) Gobierno de las TI en las Universidades: análisis sistemático de la literatura científica y no convencional. Universidad Internacional el Ecuador. Quito, Ecuador.

Fachry S., Maullana R., Fathonah N. (2018) “Analysis of Investment IT Planning on Logistic Company Using COBIT 5". Journal of Physics: Conference Series. DOI:10.1088/1742-6596/1007/1/012051

Fernández A. (2009) Análisis, planificación y gobierno de las tecnologías de la información en las universidades. Universidad de Almería. España.

Fernández A., Llorens F. (2011) Gobierno de las TI para universidades. CRUE. pp. 121-128. España. ISBN: 9788493550981

Flórez J. Lopez M. (2014) "El gobierno corporativo de las Universidades: Estudio de las 100 primeras Universidades del ranking de Shanghái”. Revista de Educación, pp. 170-187. ISSN: 0034-8082 DOI: 10.4438/1988-592X-RE-2014-364-259

Hamidovic H. (2011) Fundamentos del Gobierno de TI basados en ISO/IEC 38500. ISACA Capítulo Bogotá Boletín. Pp.4-9.

ISACA. (2012) Cobit 5. Procesos Catalizadores. Rolling Meadows. Illinois. Estados Unidos. ISBN: 9781604202489.

Marulanda C. López M. Valencia F. (2017) "Gobierno y Gestión de TI en las Entidades Públicas”. Revista Ad-Minister. Nº. 31 pp. 75 -92. ISSN 1692-0279. eISSN 2256-4322. DOI: 10.17230/ad-minister.31.5

Medina Y., Areniz Y., Rico D. (2016) Modelo estratégico para la gestión tecnológica en la organización: plan táctico de la calidad (ITIL \& ISO 20000). Instituto Tecnológico Metropolitano. Medellín, Colombia. ISBN: 978-958-5414-00-6.

Morales V. (2015) "Modelos de Gobierno TI para Instituciones de Educación Superior". Revista Politécnica. Vol. 36. No 3. ISSN 1390-0129.

Salazar C., Vela E. (2012) Gobierno de TI en Colombia. Universidad ICESI. Cali, Colombia.

Sierra L. (2012) ¿Cómo implantar el Gobierno de las Tecnologías de la Información en Instituciones de Educación Superior? Universidad ICESI. Cali, Colombia.

Solares P. (2014) Gobierno y riesgos de TI. ECORFAN, pp. 39-54. ISBN 978-097-4857-10-7

Universidad Estatal Amazónica. (2012) Estatuto orgánico de gestión organizacional por procesos de la Universidad Estatal Amazónica. Pastaza, Ecuador.

Valencia F., Marulanda C., López M. (2018) "Gobierno de las Tecnologías de la Información. Uso y Prácticas en las Entidades Públicas del Triángulo del Café”. Revista Información Tecnológica. Vol. 29. No. 3. P. 249-256. ISSN 0718-0764.

Valverde F., Mejía G., Meza D. (2017) “Análisis de la gobernanza de las Tecnologías de la Información y Comunicación al servicio del buen vivir en las universidades públicas del Ecuador". Revista Publicando, No 11. pp. 208-227. ISSN 1390-9304.

Velásquez Pérez, T., Puentes Velásquez, A., Pérez Pérez, Y. (2015) Un enfoque de buenas prácticas de gobierno corporativo de TI. Revista Tecnura, 19, 159-169. doi: 10.14483/udistrital.jour.tecnura.2015.SE1.a14

Villarreal Morales, V., (2018). Modelo de gestión y gobierno de tecnologías de la información en la Universidad Estatal Amazónica. Ecuador: Ambato

Yrigoyen, M. (2016). "Modelo de referencia de gobierno de las tecnologías de la información para instituciones universitarias". Interfases. pp. 87-115. DOI: http://dx.doi.org/10.26439/interfases2016.n009.1242 